Educational Research for Social Change (ERSC)

Volume 10 No. 1 April 2021

pp. 1-15

ersc.nmmu.ac.za

ISSN: 2221-4070

\title{
On Responses of Higher Education and Training With(in) Society Through Research, Teaching, and Community Engagement ${ }^{1}$
}

\author{
Elize van Eeden \\ ORCID No: http://orcid.org/0000-0002-4852-5522 \\ North-West University \\ Elize.VanEeden@nwu.ac.za \\ Irma Eloff \\ ORCID No: http://orcid.org/0000-0001-8306-3979 \\ University of Pretoria \\ Irma.Eloff@up.ac.za \\ Hanlie Dippenaar \\ ORCID No: http://orcid.org/0000-0001-6876-9826 \\ Cape Peninsula University of Technology \\ dippenaarh@cput.ac.za
}

\begin{abstract}
This article presents a trend analysis of the directions, nuances, and theoretical developments in community engagement (CE) practices in higher education and training (HET) environments in South Africa since 1994. It focuses on the nexus of research, teaching and learning, and community engagement. The article identifies specific associations of CE with core HET activities, illustrating how this integrated approach has brought about positive change. The research was conducted in three phases. In Phase I, purposeful sampling was used to identify the published work of leading scholars in South Africa who had engaged with the call for adopting a more transformative and collaborative approach to research such that the very act of academically engaging with(in) community became an educationally visionary act. In Phase II, the scope of the sampling was broadened to include research in multiple disciplines. In the third phase, the sampling was broadened chronologically to include research since the 1990s, and limited to the social sciences in order to conduct a trend analysis that considered historical context and growth directions in CE in the social sciences. The discussion presents an analysis of trends that emanated from research responses to CE by HET.
\end{abstract}

Keywords: community engagement, higher education and training, service learning, partnerships, collaborative research, society, trends analysis, community-based collaborative research, nuances

Copyright: @ 2021 Van Eeden, Elof \& Dippenaar

\footnotetext{
${ }^{1}$ Ethical clearance number: EFEC 8-9/2020
} 
This is an open access article distributed under the terms of the Creative Commons Attribution NonCommercial License, which permits unrestricted non-commercial use, distribution, and reproduction in any medium, provided the original author and source are credited.

Please reference as: Van Eeden, E., Eloff, I. and Dippenaar, H., (2021). On Responses of Higher

Education and Training With(in) Society Through Research, Teaching, and Community

Engagement. Educational Research for Social Change, 10 (1), 1-15.

http://dx.doi.org/10.17159/2221-4070/2021/v10i1a1

\section{Background}

Research involving community engagement (CE) amplifies the voices of researchers, educators and students, as well as communities; but the community is the epicentre of these interactions between higher education institutions (HEIs) and broader society. Through these voices (observations, experiences, and modes of communication), this article identifies the role of higher education and training (HET) in society-including its strengths, shortcomings, challenges, and (perhaps) conscious negligence. For decades, communities have been associated with HET activities but not necessarily as inclusive partners (Waghid, 1999). Awareness of the United Nations' global movement to support and attain its Sustainable Development Goal 4 (Quality Education) by 2030 is growing (https://www.un.org/sustainabledevelopment/education/). As a consequence, increasing pressure has been put on HET institutions to fulfil a key socially responsible role in communities (Owens, 2017). For communities to be considered inclusive partners in all three core visionary functions of most HET institutions (research and innovation, teaching and learning, and $\mathrm{CE}$ ) there needs to be proactive and conscious dialogue between these functional scopes of HET (Lazarus, 2007).

The key responsibilities of HEls are to address socioeconomic, developmental, and environmental needs in their immediate communities (Welch, 2016). As explained by Ogunsanya and Govender (2019), a community can refer to a broad range of university partners such as governments (national and local), businesses, nongovernmental organisations, cultural organisations, social entrepreneurial enterprises, schools, and other citizens including community leaders. Although engagement with and in communities will always be an inclusive practice as viewed from the HET perspective, the emphasis will be on engagements with communities under pressure of fewer resources, limited skills, minimal to no opportunities, and space limitations, amongst others.

Waghid (1999, p. 109) reminded academia in particular that, in the late 1990s, the "decline in the quality of life at most levels of the South African community" had already required a different approach by HET to its scope and responsiveness-as an obligatory responsibility to society. Since then, many research initiatives from most HEls in South Africa have shown active engagement in research pertaining to communities (Erasmus et al., 2015). In this article, the emphasis will be on reviewing early 21st century trends of HET responsiveness to CE, with deliberations offered on optimising HET's responsibility to embrace research, teaching, and community with enhanced societal engagement (Schuetze, 2012).

With CE still being a hybrid, or not clearly articulated educational component of HET, it has to be understood whether research with and in communities over the past two decades in South Africa can be typified as being socially responsive and enhanced through embracing the other HET visionary responsibilities. And, whatever is lacking, requires critical reflection. At the end of the 20th century, Waghid $(1999$, p. 116) viewed this as a lack of movement towards the "integrating aspects of . . . research and teaching agendas [in] more [relevant ways] . . . with community service functions." Although frequently discussed in workshops and open discussions forums, the full integration of CE with research and innovation, or in teaching and learning prerogatives in HET, seems not yet fully 
matured (B. Bouwman, personal communication with E. van Eeden, February 13, 2020). More conversations among academics to create awareness and consciousness of creativity within their own disciplines and in multidisciplinary contexts are needed to enhance societal engagement levels. In addition, funding remains an essential part of the successful implementation of CE initiatives at all HEls.

\section{Rationale}

Community engagement research in South Africa is relatively new compared to, for example, the Americas. However, South Africa is viewed as a leader in the field in Africa. Scholarship of CE in the early 21st century has developed to include community collaboration whereas earlier research accentuated the CE paradigms, sharing of best practice, and the voices of students (Kivinen et al., 2007). Currently, HEls show effort in embracing the needs of communities with whom they form a reciprocal partnership of mutual benefit. This article aims to present an identification of HEls' role in society by engaging in a trend analysis of the directions, nuances, and theoretical developments in CE practices in South Africa over the last two decades with specific reference to the research, teaching and learning, and CE nexus. It draws on Paulo Freire's (1972) concept of praxis, which implies that action and reflection are united and lead to decisive transformation in any field under study. In the same vein, participatory action research (PAR) can be viewed as action and reflection that take place at the same time, mutually igniting one another. Through praxis, a critical consciousness developsleading to transformative action central to PAR (Ollis, 2015).

The research voices identified in the article draw attention to the responses of HET in societies and highlight the strengths and challenges experienced by academics in HEls up until 2019. These voices highlight, particularly, the valuable and indispensable voice of community in research and in the teaching and learning of HET, and the importance of community collaborations in PAR opportunities that aim to empower all those involved (Dworski-Riggs \& Langhout, 2010; Kapoor \& Jordan, 2009).

\section{Research Methodology}

This article presents a trend analysis approach that considers historical context, growth directions, changing priorities, nuances, and theoretical developments in CE practices in South Africa during the last two to three decades. The trend analysis foregrounds scholarly research disseminations from the last two decades where diverse participatory methodologies were entrenched in CE- and service learning (SL)-related projects. The article positions itself at a conceptual level in order to probe the participatory methodologies that emerged in the most impactful CE and SL studies in the South African context.

The study was conducted in three phases. In Phase I, purposeful sampling to identify the published work of leading scholars in CE and SL in the country was used. The intellectual contributions ranged from student-led CE, activity systems theories and change laboratories, multidisciplinary and international collaborations, dealing with vulnerabilities, rural school partnerships, ethnography, and multiple examples where CE projects made real contributions towards improving the lives of individuals and communities. In Phases II and III, a trend analysis was followed with regards to CE practices in South Africa from the 1990s to 2019 to create an understanding of CE in HET environments. In a trend analysis, open-coded topical trends are defined in categories, followed by research questions asked on these categories (Drysdale et al., 2013). In this study, the categories were, broadly, research, teaching and learning, and CE; the trends considered historical context, growth directions, changing priorities, theoretical developments, and nuances. Trend analysis questions that the researchers in this study could have considered include: 
- Historical context as trend:

- Were researchers guided by circumstances and needs in their CE activities?

- Were researchers influenced by scholarly or popular thought in their CE understanding?

- Growth directions as trend:

- How have CE thought and activities changed over the past two to three decades?

- In what contexts are CE activities occurring?

- Changing priorities as trend:

- Which urgencies were provided as reasons for HET involvement?

- Were/are needs for CE from top-down or bottom-up initiatives?

- Theoretical developments as trend:

- What data analysis techniques were most commonly used in CE research?

- What is the range and frequency of topics commonly used in CE research?

- Nuances as trend:

- In which ways was CE understood in research?

- In which ways was CE understood in teaching and learning?

- In which ways was CE understood within HET leadership?

For the purpose of this article, the focus will only be on nuances as trend, with related theoretical developments. Nuances as trend accommodate the array of research that is associated with CE from SL and social responsiveness (SR) to, perhaps related, concepts such as experiential learning, volunteerism, work integrated learning, third sector, civic education and service, civic engagement, and citizenship (see Bawa \& Munck, 2012; Council on Higher Education, 2010; Osman \& Petersen, 2013; van Rensburg, 2007). Therefore, the authors have selected nuances as open-coded topical trends, and the questions formulated for that, to engage with the research samples selected.

\section{Ethical Considerations}

Ethical clearance for the study was granted by the Ethics Committee of the university (CPUT; EFEC 89/2020).

\section{Sample Selection}

In using the trends analysis method, the authors had to breach their own disciplinary comfort zones. A three-phase sample selection was chosen to ensure multidisciplinary openness and to accommodate diverse scholarly angles of responses from HET with and in society through research, teaching and learning, and CE. For the Phase I sample, the Scopus (scopus.com) database was selected for the period 2010 to 2019. Thereafter, in Phase II, research from a number of multidisciplinary scholars who had participated in a CE book publication for South Africa (van Eeden et al., in press) was utilised to guide the author search. In the Phase III data sample, the Google Scholar search engine was used to identify scholarly work in CE and SL research over a longer period-from 1996 to 2019-that relates to HEIs' scholarly CE visibility in South Africa.

\section{Phase I}

Multiple purposeful sampling strategies were employed to identify leading published articles by scholars in CE in South Africa. For the purpose of following a trend analysis, broad searches were conducted at the meta level in order to create a database of leading articles in the field. First, two comprehensive keyword searches were conducted, using CE and SL as major concepts. These concepts were viewed as precursors to the current concept of community-based collaborative research (CBR). Both concepts ( $C E$ and $S L$ ) are viewed as nuances of one another and the assumption was that $C E$ and SL are well established in the South African context. The Scopus database served as the primary source for the Phase I survey because it is viewed as a leading index of peer-reviewed literature and citation, 
having covered by June 2020, close to 11,7 million publishers and 69 million records (https://www.elsevier.com/solutions/scopus). For this phase, the nuances trend search for CE and SL fields were delineated from 2010 to 2019, and the first 10 articles for each field (as listed on Scopus in July 2019) were selected.

The sampling in Phase I yielded no overlap between these first 10 articles and the contributing authors' focus in the respective fields of CE and SL in the previous decade. This could be attributed to the anticipated conceptual variability, as well as linguistic and scholarly preferences from researchers who work in these fields. The first 10 articles in each of the CE and SL categories were included in the database for the current study.

\section{Phase II}

Researchers and scholars who responded in 2018 to a book project on CE in the South African context (van Eeden et al., in press) were collated as a representative list of researchers in the field at the time. With the assistance of active scholars in the broader field, invitations to participate had been extended via the South African Higher Education Community Engagement Forum; researchers from multiple scientific disciplines had been encouraged to share their most recent research findings, including collaborative work with international partners. However, chapter contributions submitted for the book did not form the database for this study. Rather, the final author list (more than 25 authors) was regarded as being indicative of leading researchers (in terms of published scholarly work or recently researched work in the field) given that all chapters had been subjected to rigorous national and international peer review. A purposefully selected list of eight chapter authors was then included as part of the Phase II data set. Any one published work on CE or SL topics by one or more of the selected authors was included in the Phase II sampling. Search results on Google were delineated to include books, book chapters, and peer-reviewed articles. The research outputs obtained from the eight authors in the second phase of sampling were added to the data set.

\section{Phase III}

In the third phase of the study, the sampling procedure was also purposive. The period of analysis was extended further back in time (1996 to 2019), and a more singular focus on the social sciences was pursued due to the strong focus in Scopus on the natural and health sciences. Phase III pursued a trend analysis to identify the main developments in research outputs from South Africa on the themes of CE and SL over the preceding 23 years (1996 to 2019). Google Scholar was used as a platform because this database is overarching, containing information from the broadest spectrum of scholarly publications available spanning social and natural sciences. These results were categorised according to the trends/topics covered and by considering some authors' preference to use CE or SL during that period. A search was conducted on the following keyword phrase: "Community engagement in South Africa" (between the years 1996 and 2019), and 140 results were retrieved. After working through all CErelated publications, the research phrase on SL was explored for the same period and reaped an outcome of 295 articles. Results retrieved from this search phrase were included to the data set according to the topics that were already listed. Because of the substantial list of accessible publications, the articles listed in the report mainly represent research outputs in the social sciences.

\section{Data Analysis and Findings}

From the range of topical trends generated by the trends analysis research framework (see earlier), questions formulated for nuances as trends were selected to engage with the full data set on responses of HET with and in society through research, teaching and learning, and CE. All three members of the research team analysed, individually, the data set to generate related aspects to the questions on nuances as trend. These preliminary sets of responses to the nuances as trend questions, representing 
CE in different HET envisioned contexts, were then identified collaboratively. The research team subsequently engaged in an iterative process of hypothesis-generating questioning, trends demarcation, and preliminary synthesising of the initial findings. From this emanated three themes that were regarded as key trends in HET community engagement research and dissemination during the last two decades:

- Community engagement expands collective collaboration;

- Community engagement amplifies voices of communities;

- Community engagement benefits universities, and instils CBR practice.

These trends, observed from scholarly engagements from the dataset, will be explicated by extracting illustrative source examples from the findings in the different phases.

\section{Phase I: Data Analysis}

\section{Community Engagement Expands Collective Collaboration}

Collective collaboration takes many forms in CE and SL in South Africa. In some studies, it manifests most prominently in the relationships between the various stakeholders. In others, it takes the form of knowledge sharing and content development. In most, collaboration is cyclical in nature and the collaboration matures over time. As illustrated below, collective collaboration presents a generative effect for those involved.

Campbell et al. $(2015$, p. 2) defined CE in biomedical research "as a collaborative relationship between a research team and the population or group of individuals targeted for research." In their study, which investigates researchers' experiences of working with a researcher-driven, population-specific community advisory board in a South African schizophrenia genomics study, they found that collaboration promoted "the protection and respect of research participants and the communities they belong to in biomedical research, and particularly in international collaborations taking place in developing countries" (Campbell et al., 2015, p. 2). Similarly, in a study on genomic biobanking research, Staunton et al. (2018) considered the relationships between those leading research projects and research team members engaging with patients. They indicated that in "reflecting upon peer engagement, respondents considered that it may be necessary for two purposes: to develop collaborations for research and to educate" (Staunton et al., 2018, p. 4); the generative effect of collaboration is evident in the fact that it frequently serves multiple purposes.

Sometimes, collective collaboration can be singular in its intent. In research on sustainable development implementation in higher education, Awuzie and Emuze (2017), for instance, identified collaboration with a reputable institutional leader in sustainable development as an implementation driver that provided competitive advantage. In other instances, collaboration is more pluralistic and can include complex, multistakeholder networks that encompass a wealth of participants and purposes. In such instances, organising principles need to be set out to guide collaborations. In an embedded four-country case study on community stakeholder engagement in biomedical HIV prevention trials, Newman et al. (2015) designed CE so that the "lead organization in each setting in consultation with community collaborators determined participant subsystems and participants" ( $p$. 4), largely because of the complexity of stakeholders across four countries. Reporting on the establishment of teaching schools in South Africa, Gravett et al. (2014) emphasised the need for the development of horizontal expertise and continued plans for collective collaboration in this regard. 
At the nuanced level, collaboration often contributes to unforeseen benefits. In a study on medical student participation in community-based experiential learning, Cameron et al. (2011, p. 374) observed the uniqueness of learning experiences during CE as learning "shifts from a competitive process focused on individual success to collaboration between medical student, healthcare provider and patient, in which all give and receive." Furthermore, they indicated that the

clinics provided both the physical and professional space for the emergence of students' professional identities. This freedom allowed them to experience both an expansion of identity through their reawakened sense of urgency, as well as an understanding that their learning and practice are enhanced by this collaboration. (Cameron et al., 2011, p. 378)

In an approach to what they called "contextualized learning," Bheekie and van Huyssteen $(2015$, p. 11) extolled the virtues of community-engaged learning when they advocated for being comfortable with discomfort. They described the process of becoming the "learner" that "enabled us to bear witness to ourselves, compelling us to become part of a collaboration through which we could articulate our own contradictions regarding higher education and inequality" (Bheekie \& van Huyssteen, 2015, p. 11). In so doing, they provided fresh perspectives on social transformation in higher education in South Africa. In a study by Glover et al. (2013) on CE activities for increasing chemistry knowledge and confidence for teachers and students, collaboration took the form of pedagogical content knowledge sharing between colleagues from a university academic department and the provincial department of education. Collaborative knowledge sharing and knowledge building can be seen across numerous studies with nuances of CE.

\section{Community Engagement Amplifies Voices of Communities}

A study by Moodley and Beyer (2019) viewed community consultation as a "hallmark of Ubuntu" (p. 615). They also noted that CE was "often implemented in a tokenistic manner as an ancillary component of research" (Moodley \& Beyer 2019, p. 613). This way of approaching research as a social responsibility also is noticeable in Bergh et al. (2016), in which the role of undergraduate medical students' opportunities in regional quality improvement projects were observed (see also de Villiers et al., 2017). The in community collaborations, with emphasis on student teamwork, appear to have weighed still more strongly in the recent decade than the with community's voice (Bergh et al., 2016; Naudé, 2012). However, it may frequently be a matter of all engagement inspired towards making a one-way difference without community.

\section{Community Engagement Benefits Universities and Instils CBR Practice}

Awuzie and Emuze's (2017) research was on the sustainable development agenda associated with HEls as leaders, also viewed as an agenda that benefits HEls because it draws the attention from society to HEls' educational leadership. CE, together with cost-related factors and regulatory matters amongst others, were viewed as challenging drivers for HEls' progress towards implementation at that time. In a collaborative effort by the University of Cape Town and the University of Stellenbosch, scholars engaged in what they called, a "robust Community Engagement (CE) strategy" (Staunton et al., 2019, p. 2) to "develop and implement a process for involving potential participants in biobanking research at Tygerberg Hospital to develop governance policies" and to translate that process into a generalisable model (Staunton et al., 2018, as quoted in Staunton et al. 2019, p. 2). Three scientific reports on this project were produced (Staunton et al., 2019; Staunton \& Moodley, 2016; Staunton et al., 2018). As observed by Bergh et al. (2016), the involvement of students in community as another (experiential) SL opportunity, and the benefit of this kind of CE visibility for HEls, cannot be underestimated (see also Bheekie \& van Huyssteen, 2015; Cameron et al., 2011; de Villiers et al., 2017; Srinivas et al., 2015). Informed curriculum improvements complement the strategic vision of faculties (see, for example, Cameron et al., 2011; Glover et al., 2013). More disciplinary-specific beneficence 
from CE activities was also described by Paphitis and Kelland (2015). HEls have also been criticised interpreting CE too narrowly, rather than considering an "adaptive [leadership knowledge] engagement" approach through a community lens with a changing focus in mind (Preece, 2016, p. 104).

\section{Phase II: Data Analysis \\ Community Engagement Expands Collective Collaboration}

There is a growing awareness of the essential role of community partners in any community interactions (Albertyn \& Daniels, 2009; Albertyn \& Erasmus, 2014). This is explored by McMillan (2011) who looked at what happens when "educators start working and learning with community members" (p. 564). The reciprocal nature of CE implies collaborative communication and dialogue, especially in the social and the educational sciences. Burman et al. (2017) also engaged in HIV preventative research (see the earlier approach in the health sciences in Phase I) through a framework inclusive of experiential learning in an engaged scholarship. SL experiences with students were also visible in an array of sciences observed in this data set, of which Jordaan's (2014) undergraduate experience in the faculty of engineering at the University of Pretoria serves as a typical example.

One of the goals of CE is to create awareness of differential power relations to foster collaborative forms of interdependence-and not dependence. When a community recognises the reciprocal nature of CE and negotiated outcomes thereof in a CE project, it is more likely to become empowered, feel valued as equal partner, and valued as a source of knowledge (Bender, 2008).

\section{Community Engagement Amplifies Voices of Communities}

The dialogical nature of CE emphasises the voice of community to be heard. O'Brien (2012) stressed the challenge of negotiated power relations when interacting with the community and emphasised that $\mathrm{CE}$ relationships built on dialogue are more likely to bring about social change. The dialogic nature of communication (Freire, 1972) as part of CE requires time and effort (Schmied et al., 2010) because there is an underlying power relationship that needs to be acknowledged (Osman \& Attwood 2007).

As pointed out by Wood (2016, p. 685), CE partnerships require an "ability to empathize with the lived experiences of community participants" and to hear their voices. This requires communication from both parties and is the essence of successful CE. Acknowledging the voice of community and recognising differences in expectations and choices will determine successful outcomes for all. Petker and Petersen (2014) pointed out that the success of CE, such as in SL projects, is dependent on the relationship between all parties.

Machimana et al. (2018, p. 177) emphasised the inclusion of "often silent voices of non-researcher partners." These authors also found that regular feedback sessions could assist in assessing the strengths and weaknesses of partnerships. They suggested that this should be a two-way process of reflexive engagement with both parties providing feedback to the other-which would ensure realistic expectations and enhance transformation. This concurred with the findings of Strier (2011) who accentuated the importance of mutual respect and sharing of knowledge.

Without doubt, it may be said that the voice and agency of community in CBR is essential in the success of CE research as per HET's vision and requirement, and that any top-down approach or disregard of the power of community is not conducive to success. Therefore, the first and most important trend identified, is the importance of recognising the inherent power of the centre of engagement-which 
is the community. By the very nature of $\mathrm{CE}$, there is a strong focus in the literature on teaching and learning and the sharing of best practice.

\section{Community Engagement Benefits Universities and Instils CBR Practice}

The core strategic positioning of CE in higher education's aims (internationally and in South Africa) has been widely acknowledged in research (Wood, 2016). There was a call for HEls to acknowledge the needs of communities-expressed as "social justice pedagogy" (Petersen \& Henning, 2018, p. 436). Petersen and Henning (2018, p. 436) rightly observed that universities' "service to/in society and community is not new," and that it is not about "doing good," but being in touch with the needs of society (Boyer, 1996 as cited in Petersen \& Henning, 2018, p. 436). SL emerged as a structured form of CE where there is a strong focus on student engagement in communities (Kruss et al., 2012; van Schalkwyk \& Erasmus, 2011) based on Dewey's (1938) ideas of experiential learning. SL became a way to address the social responsibility of HEls while simultaneously enhancing teaching and learning of students (Mtawa \& Nkoma, 2020; Osman \& Attwood, 2007). Although it is noted by Preece (2016) that universities as a macro-level facilitator tend to recognise the "good" in CE-based knowledge, there appears to be some limiting "institutional governmentality" (p. 108) regarding students' contributions to sustainable community outcomes. Akpan et al. $(2012$, p. 2) pointed out that $C E$, at the time, remained, at best, unstructured and a "marginal, uncoordinated necessity" in South African universities.

\section{Phase III: Data Analysis}

\section{Community Engagement Expands Collective Collaboration}

In Phase III of the data analysis, the three key trends were again prevalent. In the first instance, there was a strong accent on the importance of a collective collaboration with partners, which include community partners, nongovernmental organisations, and partners from industry (McMillan \& Stanton, 2014). These authors further emphasised the importance of collaboration and building relationships, which they described as "central to ethical and sustainable CE" (McMillan \& Stanton, 2014, p. 66) and often stretch across complex boundaries. Relationships with partners were seen as the essence of community involvement. Van Schalkwyk and Erasmus (2011, p. 68) pointed out that "trusting, respectful relationships with external stakeholders enables the university to realise its goals of relevant teaching, learning and research." By 2007, the nature of CE-HET collaboration surfaced in Mitchell and Humphries' (2007) remark that SL practitioners should move beyond notions of "benefit" to explore the "paradoxical and ambivalent nature of the engagement between higher education institutions and that are the object of service" (p. 47). It was strongly confirmed that collaboration with all partners is an important aspect in research with CE. As pointed out by du Plessis and van Dyk (2013, p. 9), SL is not "service to or on behalf of others, but would be learning and serving together with all involved" - which underlines the collaborative nature of community involvement. This was also pointed out by Mutero and Govender $(2019$, p. 3 ) in their findings on the importance of "collaborative strategic thinking, strategic planning and the collective implementation of initiatives" which leads to "emancipatory, sustainable and scalable" collaboration.

\section{Community Engagement Amplifies Voices of Communities}

With respect to the second trend identified in the analysis focuses on the importance of the voice of communities, van Schalkwyk and Erasmus (2011) expressed the view that effective SL depends on ongoing collaborative research that enables community participants to make their voices heard and should include "emancipatory teaching approaches and transformative learning for community members" (p. 78). From du Plessis \& van Dyk (2013) came the imperative to HEls that academic research or SL activity cannot work in communities without negotiating (allowing a voice), partnering, and participating with them. 


\section{Community Engagement Benefits Universities and Instils CBR Practice}

Ever since CE initiatives and SL projects were explored and incorporated into the vision and mission of HEls in South Africa (that, in particular, date from the last decade of the 20th century) universities have been investigating the benefits in undertaking this, previously too dormant, part of its vision in addition to teaching and learning, and research (Kruss et al., 2012). It has often meant extra responsibilities added to the workload of lecturers, unforeseen risks when taking students off campus, and funding implications. A definite trend over the years has been research on the benefits of CE for HEls. There has been a strong focus on the advantages for students and additional research opportunities, especially in light of the expected graduate attributes and expectations from society on what a newly graduated employee should look like. Preece and Manicom (2015) pointed out that SL was introduced in response to the postapartheid policy agenda for higher education in South Africa to create a sense of community responsibility amongst higher education students, and to redress the inequities of apartheid while acknowledging higher education as being for the public good. As pointed out by Mtawa and Nkomo (2020), students develop citizenship and critical social values through SL. In addition, there is emerging scholarship on research in CE and $\mathrm{SL}$ in which the changing role of universities in society is accentuated-moving from an ivory tower of academic isolation and elitism to partnership and service to society (Kivinen et al., 2007).

\section{Limitations of the Study}

The authors realise that this article provides a mere glimpse of the valuable work done by CE scholars, leaders, and forerunners in the partnership between HEls and communities. Limitations still strongly prevalent in CE in South Africa are the narrow to total lack of an engaged community voice in some instances, and the "how's" of proactive collaborative research between HEls as stakeholders and communities. Not to be ignored either, is that a one-size-fits-all approach to CE for the diverse disciplines and faculties in HEls is likely to fail because the point of entry to communities varies widely (as observable in all three sets of data analyses). This emphasises the mammoth task requiring the attention of all sciences in HEls, namely, to further engage in research and related activities that will complement the engaging with communities in equitable, healthy, and sustainable ways in unique engagement contexts.

\section{Conclusion}

This article provides reflections on the nuances of CE as a trend that has emanated from research by scholars in the field in South Africa (and in collaboration with international scholars) from the late 1990 s to 2020 . The study illustrates how the triad of research, teaching \& learning, and CE serves as an accelerator of critical learning outcomes for students (SL opportunities), researchers (collaboration opportunities), and community stakeholders (having a voice in research endeavours). The golden thread through the study is the importance of a form of collaboration with communities that will differ in focus and vision from faculty to faculty. Prominence of the voice of community partners requires more attention, and needs to be ingrained in the process in order for the research, teaching and learning, and CE nexus to be optimised (Kitching, 2016).

The insight gained from the findings of a three-phase trend analysis data set was significant. In the Scopus research publications reviewed, CE researchers seemed to be working with communities to find mutually beneficial solutions related, mainly, to the natural and health sciences (Newman et al., 2015). It is thus an approach towards collaborating scholarly research practice with only selective community members on a short-term research scale. HIV prevention research and HIV cure research seems to have dominated in the last decade, and the role of CE appears to have instilled more awareness among health researchers in the HIV field since the early 1980s (Staunton \& Moodley, 2016). CE in health research referenced globally as community stakeholder engagement (CSE) also 
featured as a noticeable effort to accentuate the necessity to better articulate the meaning of CE to transform from a "within" community mode to a more practical "with community" approach (Newman et al., 2015, 2018). It's as if in recent research in the field of the health sciences, there is an awakening that local views on research are important to adequately inform governance policies and frameworks, although it was also sometimes viewed that empirical evidence on CE practices and processes in and of themselves may fall short (see Staunton \& Moodley, 2016, p. 14; Staunton et al., 2018, p. 1).

The CE research disseminated in the multidisciplinary and the social sciences exposed a different nuance of engagement as approach. In the research on all the data sets, both CE and SL concepts as nuances were not necessarily applied consistently by scholarly research in projects related to community. Although SL in community was seemingly approached with intentions to consciously embrace the voice of communities, a plea for more community dialogue as a more sustainable way of CE practice was voiced.

Although this study provides a glimpse of the development of CE over the last decades in South Africa, this is a field that is in flux and that will experience change subject to the demands of the current global pandemic, which is unprecedented in South Africa (Staunton et al., 2020). New horizons are being explored to ensure safety of communities, students, and academic staff in CE research. Much more research in this regard will also have to be done in this field to determine whether online projects will reach communities and whether the emotional and physical distance between students and communities would have the same potential for development and reciprocal learning. This study reports on past CE trends but can predict future innovation that will contribute to the strengthening of community-based research in $\mathrm{HEI}$.

\section{Acknowledgement}

The authors would like to thank Mrs Christel Oosthuizen (CPUT) for her valued assistance in the identification of sources from Scopus and Google Scholar for the Phase III data set.

\section{References}

Akpan, W., Minkley, G., \& Thakrar, J. (2012). In search of a developmental university: Community engagement in theory and practice. South African Review of Sociology, 43(2), 1-4. https://doi.org/10.1080/21528586.2012.694239

Albertyn, R., \& P. Daniels. (2009). Research within the context of community engagement. In E. Bitzer (Ed.), Higher education in South Africa: A look behind the scenes (pp. 409-428). Sun Press.

Albertyn, R., \& Erasmus, M. (2014). An introductory perspective on the knowledge enablement landscape. In R. Albertyn \& M. Erasmus (Eds.), Knowledge as enablement: Engagement between higher education and the third sector in South Africa (pp. 21-37). Sunmedia.

Awuzie, B., \& Emuze, F. (2017). Promoting sustainable development implementation in higher education universities in South Africa. International Journal of Sustainability in Higher Education, 18(7), 1176-1190. https://doi.org/10.1108/IJSHE-09-2016-0167

Bawa, A. C., \& Munck, R. (2012). Foreword: Globalizing civic engagement. In L. Mcllrath, A. Lyons, \& R. Munck (Eds.), Higher education and civic engagement: Comparative perspectives. Palgravemacmillan.

Bender, C. J. G. (2008). Curriculum enquiry about community engagement at a research university, South African Journal of Higher Education, 22(6), 1154-1171. https://doi.org/10.4314/sajhe.v22i6.44248 
Bergh, A., Bac, M., Hugo, J., \& Sandars, J. (2016). "Making a difference": Medical students' opportunities for transformational change in health care and learning through quality improvement projects. BMC Medical Education, 16(171), 1-8. https://doi.org/10.1186/s12909$\underline{016-0694-1}$

Bheekie, A., \& van Huyssteen, M. (2015). Be mindful of your discomfort: An approach to contextualized learning. International Journal of Research on Service-Learning and Community Engagement, 3(1), 1-13. https://doi.org/10.37333/001c.21560

Burman, C. J., Aphane, M. A., \& Mollel, N. M. (2017). The taming wicked problems framework: Reflections in the making. Journal for New Generation Sciences, 15(1), 51-73. https://www.researchgate.net/publication/324646298 The Taming Wicked Problems Framew ork reflections in the making

Cameron, D., Wolvaardt, L., van Rooyen, M., Hugo, J., Blitz, J., \& Bergh, A-M. (2011). Medical student participation in community-based experiential learning: Reflections from first exposure to making the diagnosis. South African Family Practice, 53(4), 373-379. https://doi.org/10.1080/20786204.2011.10874117

Campbell, M. M., Susser, E., de Vries, J., Baldinger, A., Sibeko, G., Mndini, M. M., Mqulwana, S. G., Ntola, O. A., Ramesar, R. S., \& Stein, D. J. (2015). Exploring researchers' experiences of working with a researcher-driven, population-specific community advisory board in a South African schizophrenia genomics study. BMC Medical Ethics, 16, Article 45. https://doi.org/10.1186/s12910-015-0037-5

Council on Higher Education (CHE). (2010). Community engagement in South African higher education South Africa. Policy document, Ministry of HET, Kagisano No. 6, Jan.

Dewey, J. (1938). Experience and education. Macmillan.

de Villiers, M., van Schalkwyk, S., Blitz, J., Couper, I., Moodley, K., Talib, Z., \& Young, T. (2017). Decentralised training for medical students: A scoping review. BMC Medical Education, 17(196), 113. https://doi.org/10.1186/s12909-017-1050-9

Drysdale, J. S., Graham, C. R., Halverson, L. R., \& Spring, K. J. (2013). Analysis of research trends in dissertations and theses studying blended learning. Internet and Higher Education, 17(1), 90-100. https://doi.org/10.1016/i.bbr.2011.03.031

du Plessis, C., \& van Dyk, A. (2013). Integrating the community voice into service learning: Engaging with communities. In R. Osman \& N. Petersen (Eds.), Service learning in South Africa (pp. 59-84). Oxford Press.

Dworski-Riggs D., \& Langhout, R. D. (2010). Elucidating the Power in empowerment and the participation in participatory action research: A story about research team and elementary school change. American Journal of Community Psychology, 45, 215-230. https://doi.org/10.1007/s10464-010-9306-0

Erasmus, M., Seale, I., \& Venter, K. (2015). Knowledge sharing for the development of service learning champions. Journal for New Generation Sciences, 13(2), 147-163. http://hdl.handle.net/11462/772

Freire P. (1972). Pedagogy of the oppressed. Penguin.

Glover, S. R., Sewry, J. D., Bromley, C. L., Davies-Coleman, M. T., \& Hlengwa, A. (2013). The implementation of a service-learning component in an organic chemistry laboratory course. Journal of Chemical Education, 90, 578-583. https://doi.org/10.1021/ed2008153 
Gravett, S., Petersen, N., \& Petker, G. (2014). Integrating foundation phase teacher education with a "teaching school" at the University of Johannesburg. Education as Change, 18(1), 107-S119. https://doi.org/10.1080/16823206.2013.877357

Jordaan, M. (2014). Community-based project module: A service-learning module for the Faculty of Engineering, Built Environment and Information Technology at the University of Pretoria. International Journal for Service Learning in Engineering, Special Edition, 269-282. http://hdl.handle.net/2263/45092

Kapoor, D., \& Jordan, S. (2009). Education, participatory action research, and social change: International perspectives. Palgrave Macmillan.

Kitching, A. E. (2016). A participatory paradigm for an engaged scholarship in higher education: Action leadership from a South African perspective. Educational Research for Social Change, 5(1), 144-147. Retrieved April 13, 2021, from http://www.scielo.org.za/scielo.php?script=sci arttext\&pid=S2221$40702016000100011 \& \operatorname{lng}=$ en\&tlng=en.

Kivinen, O., Hedman, J., \& Kaipanen, P. (2007). From elite university to mass higher education: Educational expansion, equality of opportunity and returns to university education, Acta Sociologica, 50(3), 231-247. https://doi.org/10.1177/0001699307080929

Kruss, G., Haupt, G., Visser, M., \& Mogau Aphane, M. (2012). Academic interaction with social partners: Investigating the contribution of universities to economic and social development. HSRC Press.

Lazarus, J. (2007). Embedding service learning in South African higher education: The catalytic role of the CHESP initiative. Education as Change, 11(3), 91-108. https://doi.org/10.1080/16823200709487182

Machimana, E. G., Sefotho, M. M., \& Ebersöhn, L. (2018). What makes or breaks higher education community engagement in the South African rural school context: A multiple-partner perspective. Education, Citizenship and Social Justice, 13(2), 177-196. https://doi.org/10.1177/1746197917731353

McMillan, J. (2011). What happens when the university meets the community? Service learning boundary work and boundary workers. Teaching in Higher Education, 16(5), 553-564. http://dx.doi.org/10.1080/13562517.2011.580839

McMillan, J., \& Stanton, T. (2014). "Learning Service" in international contexts: Partnership-based service-learning and research in Cape Town, South Africa. Michigan Journal of Community Service Learning. http://hdl.handle.net/11427/24813

Mitchell, M., \& Humphries, H. (2007). From notions of charity to social justice in service-learning: The complex experience of communities. Education as Change, 11(3), 47-58. https://doi.org/10.1080/16823200709487178

Moodley, K., \& Beyer, C. (2019). Tygerberg research ubuntu-inspired community engagement model: Integrating community engagement into genomic biobanking. Biopreservation and Biobanking, 17(6), 613-624. https://doi.org/10.1089/bio.2018.0136

Mtawa, N. N., \& Nkhoma, N. M. (2020). Service-learning as a higher education pedagogy for advancing citizenship, conscientization and civic agency: A capability informed view. Higher Education Pedagogies, 5(1), 110-131. https://doi.org/10.1080/23752696.2020.1788969

Mutero, I. T., \& Govender, I. G. (2019). Moving from transactional partnerships to collaborative university community engagement: A case study evaluating creative placemaking in KwaZulu-Natal Province, South African Review of Sociology, 50(1), 3-17. https://doi.org/10.1080/21528586.2019.1632578 
Naudé, L. (2012). At the cultural crossroads: Intergroup psychology among students in a servicelearning programme. Current Psychology, 31, 221-245. https://doi.org/10.1007/s12144-0129142-5

Newman, A., Slack, C., \& Lindegger, G. (2018). Commentary on "A framework for community and stakeholder engagement: Experiences from a multicenter study in Southern Africa." Journal of Empirical Research on Human Research Ethics, 13(4), 333-337. https://doi.org/10.1177/1556264618783560

Newman, P. A., Rubincam, C., Slack, C., Essack, Z., Chakrapani, V., Chuang, D., Tepjan, S., Shunmugam, M., Roungprakhon, S., Logie, C., Koen, J., \& Lindegger, G. (2015). Towards a science of community stakeholder engagement in biomedical HIV prevention trials: An embedded four-country case study. PLoS ONE, 10(8), 1-20. https://doi.org/10.1371/journal.pone.0135937

O’Brien, F. (2012). Constructing service learning in South Africa: Discourses of engagement. In J. Preece, P. G. Ntseane, O. M. Modise, \& M. Osborne (Eds.), Community engagement in African universities: Perspectives, prospects and challenges (pp. 197-213). Leicester NIACE.

Ogunsanya, O. F., \& Govender, I. G. (2019). University-community engagement: Current tensions and future trends. International Journal of African Higher Education, 6(1), 59-74. https://doi.org/10.6017/ijahe.v6i1.11089

Ollis, T. (2015). Activism, reflection, and Paulo Freire: An embodied pedagogy. In M. A. Peters \& T. Besley (Eds.), Paul Freire: The global legacy (pp. 517-527). Peter Lang.

Osman, R., \& Attwood, G. (2007). Power and participation in and through service learning. Education as Change, 11(3), 18-21. https://doi.org/10.1080/16823200709487175

Osman, R., \& Petersen. N. (2013). Service learning in South Africa. Oxford University Press.

Owens, T. L. (2017). Higher education in the sustainable development goals framework. European Journal of Education: Research, Development and Policy, 52(4), 414-420. https://doi.org/10.1111/ejed.12237

Paphitis, S. A., \& Kelland, L. (2015). Challenging the dominant ideological paradigm: Can community engagement contribute to the central epistemic aims of philosophy? South African Journal of Philosophy, 34(4), 419-432. https://doi.org/10.1080/02580136.2015.1105481

Petker, G., \& Petersen, N. (2014). Service learning in foundation phase teacher education: Experiential learning opportunities for student teachers. South African Journal for Childhood Education, 4(3), 122-135. https://doi.org/10.4102/sajce.v4i3.231

Petersen, N., \& Henning, E. (2018). Service learning and the practice of social justice and care. Journal of Human Behaviour in the School Environment, 28(4), 436-448. https://doi.org/10.1080/10911359.2017.1418697

Preece, J. (2016).Negotiating service-learning through community engagement: Adaptive leadership, knowledge, dialogue and power. Education as Change, 20(1), 104-125. http://dx.doi.org/10.17159/1947-9417/2016/562

Preece, J., \& Manicom, D. (2015). The pedagogic contribution of community spaces and environments in service learning projects. Alternation Special Edition, 16, 115-140. http://alternation.ukzn.ac.za/Files/docs/22\%20SpEd16/06\%20Preece\%20F.pdf

Schmied, V., Mills, A., Kruske, S., Kemp, L., Fowler, C., \& Homer, C. (2010). The nature and impact of collaboration and inergrated service delivery for pregnant women, children, families. Journal of Clinical Nursing, 19, 3516-3526. https://doi.org/10.1111/i.1365-2702.2010.03321.x 
Schuetze, H. G. (2012). Universities and their communities: Engagement and service as primary mission. In L. Mcllrath, A. Lyons, \& R. Munck (Eds.), Higher education and civic engagement. comparative perspectives (pp. 61-77). PalgraveMacmillan.

Srinivas, S. C., Paphitis, S. A., Ncomanzi, A. S., Tandlich, R., \& Bradshaw, K. (2015). Service-learning based environmental health promotion activities for pharmacy students: Educating youth on the safe disposal of medicines and used sharps. Journal for New Generation Sciences, 13(3), 182-196. https://journals.co.za/doi/pdf/10.10520/EJC185119

Staunton, C., Akin, A., Bassa, F., \& Moodley, K. (2019). Negotiating requests for reimbursement for community engagement: Challenges in developing an educational video for genomic biobanking research in South Africa. Journal of Empirical Research on Human Research Ethics, 14(5), 501-503. https://doi.org/10.1177/1556264619856223

Staunton, C., \& Moodley, K. (2016). Community engagement for biobanking research: Perspectives from Africa. Asia Pacific Biotech News, 20(2), 14-26. https://www.asiabiotech.com/20/2002/20020024x.html

Staunton, C., Swanepoel, C., \& Labuschagne, M. (2020). Between a rock and a hard place: Covid-19 and South Africa's response. Journal of Law and the Biosciences, Article Isaa052. https://academic.oup.com/ilb/advance-article/doi/10.1093/ilb/lsaa052/5868300

Staunton, C., Tindana, P., Hendricks, M., \& Moodley, K. (2018). Rules of engagement: Perspectives on stakeholder engagement for genomic biobanking research in South Africa. BMC Medical Ethics, 19(13), 1-10. https://doi.org/10.1186/s12910-018-0252-y

Strier, R. (2011). The construction of university-community partnerships: entangled perspectives. Higher Education, 62, 81-97. https://doi.org/10.1007/s10734-010-9367-x

van Eeden, E. S., Eloff, I., \& Dippenaar, H. (Eds.). (in press). Community engagement research in South Africa: Histories, methods, theories, and practice. van Schaik.

van Rensburg, W. (2007). CSL, multiliteracies, and multimodalities. Education as Change, 11(3), 183189. https://doi.org/10.1080/16823200709487187

van Schalkwyk, F., \& Erasmus, M. (2011). Community participation in higher education service learning. Acta Academica, 43(3), 57-82.

http://scholar.ufs.ac.za:8080/bitstream/handle/11660/2810/academ v43 n3 a3.pdf? sequence= 1\&isAllowed =y

Waghid, Y. (1999). Engaging universities and society through research, teaching and service. South African Journal for Higher Education, 13(2), 109-117. https://journals.co.za/doi/10.10520/AJA10113487972

Welch, M. (2016). Engaging higher education: Purpose, platforms, and programs for community engagement. Stylus.

Wood, L. (2016). Community development in higher education: How do academics ensure their community-based research makes a difference? Community Development Journal, 52(4), 685-701. https://doi.org/10.1093/cdj/bsv068 